\title{
POTENCIALIDADES DA IMPRESSÃO 3D SOB A PERSPECTIVA DO DESIGN: uma análise do setor de joalheria em Belo Horizonte ${ }^{1}$
}

\author{
Monteiro, Marco Túlio Ferreira; Mestrando; Universidade do Estado de \\ Minas Gerais. \\ tuliomonteiro@gmail.com
}

Krucken, Lia; Dr. ; ; Universidade do Estado de Minas Gerais.

lia.krucken@gmail.com

\author{
Lana, Sebastiana Luiza Bragança; Dr.a ; Universidade do Estado de Minas \\ Gerais. \\ sebastiana.lana@gmail.com
}

\begin{abstract}
Resumo: A impressão tridimensional (3D) vem se desenvolvendo e multiplicando suas aplicações em diversos segmentos, os processos se adaptam bem como os materiais se diversificam com diferentes propriedades de acordo com as necessidades específicas de cada aplicação. Neste contexto de mudanças conceituais nos processos produtivos e nas cadeias de fabricação muitas questões surgem, porém o cenário é complexo, abrangente a vários segmentos de mercado e várias demandas específicas, portanto segmentos pioneiros na aplicação podem servir de base para o entendimento de algumas dessas questões. Este artigo teve como objetivo analisar as potencialidades, barreiras e oportunidades da aplicação da impressão tridimensional no setor de joalheria. No caso específico desse segmento, o serviço de impressão se encontra terceirizado e as empresas já tem sua atuação consolidada, podendo servir como referência de estudo. 0 estudo se baseou em entrevistas às empresas mais sedimentadas e com foco no segmento de joalheria para investigação da sua situação no neste mercado. Observou-se que apesar da impressão já estar incorporada em algumas partes do processo de fabricação de joias, ainda tem espaço para ampliar sua utilização, abrangendo outras etapas do processo produtivo, porém isto ainda não acontece devido à situação de mercado para o fornecimento dos maquinários e insumos utilizados na impressão, estes, ainda exclusividade de poucas empresas.
\end{abstract}

\footnotetext{
${ }^{1}$ Artigo desenvolvido na disciplina Design para Sustentabilidade da professora Lia Krucken, sob orientação das professoras Sebastiana Lana e Lia Krucken, no Programa de Pós Graduação em Design da Universidade do Estado de Minas Gerais, em 2013.
} 
Palavras chave: Impressão 3-D, Joalheria, Prestadoras de serviços, Design, Materiais.

\begin{abstract}
Three-dimensional printing (3D) has been developing and multiplying its applications in various market segments, the processes and the materials are been adapting and diversifying according to the specific needs of each application. In the context of manufacturing, issues arise in production and assembly processes, the scenario is complex, approaching several market segments and specific demands. The segments pioneers in $3 D$ printing use can be a basis for the understanding some of these issues. This paper is focused in analyse the potential, barriers and opportunities of application of three-dimensional printing in the jewellery sector. In this segment, the print service is outsourced, and these companies have consolidated its operations, so can be a reference for study. The data was collect by interviews in jewellery 3D printing service companies, to know their situation in this market. It was observed that, despite $3 D$ printing already be incorporated in some stages of the manufacturing process of jewels, it can expand its use, covering other steps of the manufacturing process, but it still doesn't happen because the supply market situation, including expensive costs of machinery and supplies because of exclusivity actuation of few suppliers.
\end{abstract}

Key words: 3-D Printing, Jewellery, Service Bureaus, Design, Materials.

\title{
1. INTRODUÇÃO
}

A impressão tridimensional vem sendo muito comentada nos últimos tempos e a cada dia ganha mais espaço, ela já é considerada uma tecnologia muito promissora e com potencial para mudar drasticamente a forma de se fabricar. Diferentemente do que ocorreu no início de sua utilização, quando foi utilizada basicamente nas etapas de projeto para a confecção de protótipos a fim de se fazerem avaliações ainda na fase de desenvolvimento, agora, com o avanço da tecnologia, ela vem encontrando cada vez mais espaço sendo utilizada em cada vez mais etapas da fabricação (ANDERSON, 2012, p. 16).

Basicamente esta tecnologia proporciona a fabricação de diversos componentes físicos, sejam eles peças, protótipos, modelos, réplicas, em 3 dimensões (3D), através das informações da geometria da peça contidas em um arquivo digital que geralmente é elaborado em um sistema de computador (CAD), onde as informações contidas são utilizadas pela máquina, para a construção da peça física, sistematicamente, camada por camada, até que se obtenha a peça completa (VOLPATO, 2007, p. 3).

A grande mudança esperada está na popularização desta tecnologia, que já vem sendo percebida em alguns segmentos específicos, porém ainda de forma muito pontual como ferramenta para a fabricação de produtos acabados, e não mais apenas para a confecção de modelos e protótipos, como já é utilizada ha algum tempo, explicitando uma tendência de simplificação e democratização da produção chegando até a uma fabricação digital e pessoal, claramente defendida por alguns estudiosos (GERSHENFELD, 2012, p. 45). 
Todas essas mudanças trazem novos paradigmas, pois a tecnologia empregada possui características específicas que geram restrições para sua utilização em alguns segmentos, porém estas mesmas especificidades são potencializadoras para a aplicação em outros segmentos, e trazem novos parâmetros para a fabricação e para o mercado.

Alguns segmentos vêm sentindo as influências da tecnologia, mesmo que ainda de forma lenta, ela está ocupando mais espaços a cada dia e trazendo diversas oportunidades para o mercado, como será empregada e como o potencial dessa nova tecnologia afetará os diferentes segmentos de mercado com suas particularidades, gerando assim um cenário complexo e com inúmeras questões ainda por serem respondidas.

Este mercado já utiliza a tecnologia de impressão tridimensional regularmente como parte do processo produtivo em algumas etapas de fabricação da joia, portanto pode servir de base para formar uma visão sobre sua influência e servir de referência para outros segmentos.

Esta pesquisa teve como objetivo analisar potencialidades, barreiras e oportunidades das empresas prestadoras de serviço impressão de 3D voltadas para o mercado de joalheria na cidade de Belo Horizonte, sendo este artigo estruturado em 3 partes. Primeiramente apresenta-se um panorama sobre as tecnologias de impressão tridimensional, passando posteriormente para a análise da utilização da impressão 3D na joalheria em Belo Horizonte e então as conclusões do estudo.

\section{METODOLOGIA}

Para este artigo foi utilizada a metodologia dividida em etapas conforme segue:

- Estudo das diferentes tecnologias de impressão tridimensional e suas características gerais e especificidades inerentes a seus processos de fabricação;

- Entrevistas com empresas de prestação de serviços de impressão 3D para o segmento de joalheria em Belo Horizonte.

- Análise das potencialidades, barreiras e oportunidades da tecnologia para o segmento estudado.

Foi realizado um levantamento sobre as principais características das tecnologias de impressão 3D e suas especificidades. Também foram levantadas suas principais influências quando utilizada como ferramenta de produção, com o objetivo de entender seu potencial futuro de aplicação e suas influências no mercado e meio ambiente, seus pontos negativos e positivos.

Foram escolhidas empresas de prestação de serviço de impressão tridimensional na cidade de Belo Horizonte que tivessem como foco o atendimento ao segmento de joalheria para que servissem de referência no estudo da situação da impressão 3D. Foram feitas entrevistas com os proprietários e fundadores das três mais sedimentadas empresas para que o panorama fosse o retrato da experiência e vivência no segmento.

As entrevistas, realizadas no período de 02 de outubro a 27 de novembro de 2013, foram qualitativas abordando o panorama da utilização da impressão 3D, porém procurando focar no entendimento dos processos e materiais utilizados, bem como no fornecimento das matérias primas empregadas. 


\section{PANORAMA SOBRE A IMPRESSÃO 3D}

Todas as técnicas e processos desenvolvidos ao longo da história da impressão 3D vêm sendo progressivamente aprimorados, dando origem aos sistemas atuais.

No início da comercialização dos sistemas de impressão 3D, eles foram basicamente utilizados em etapas do projeto de produtos, principalmente em estudos formais, com o objetivo de aumentar a confiabilidade das decisões tomadas durante o processo de desenvolvimento. Em seguida começaram a ser empregados com a finalidade de testes, na engenharia, análise e planejamento e, finalmente na fabricação de ferramental, para testes, avaliação e melhorias de nos processos produtivos convencionais e, por último diretamente na produção de bens acabados para o mercado (VOLPATO, 2007, p. 12).

No campo do design a tecnologia foi aplicada pela primeira vez com a função de confeccionar modelos e protótipos, devido ao ganho de tempo e velocidade na construção de modelos funcionais em relação aos tradicionalmente feitos à mão, hoje ela se encontra consolidada como ferramenta do processo de desenvolvimento de produtos (DIMITROV, SCHREVE e DE BEER, 2006).
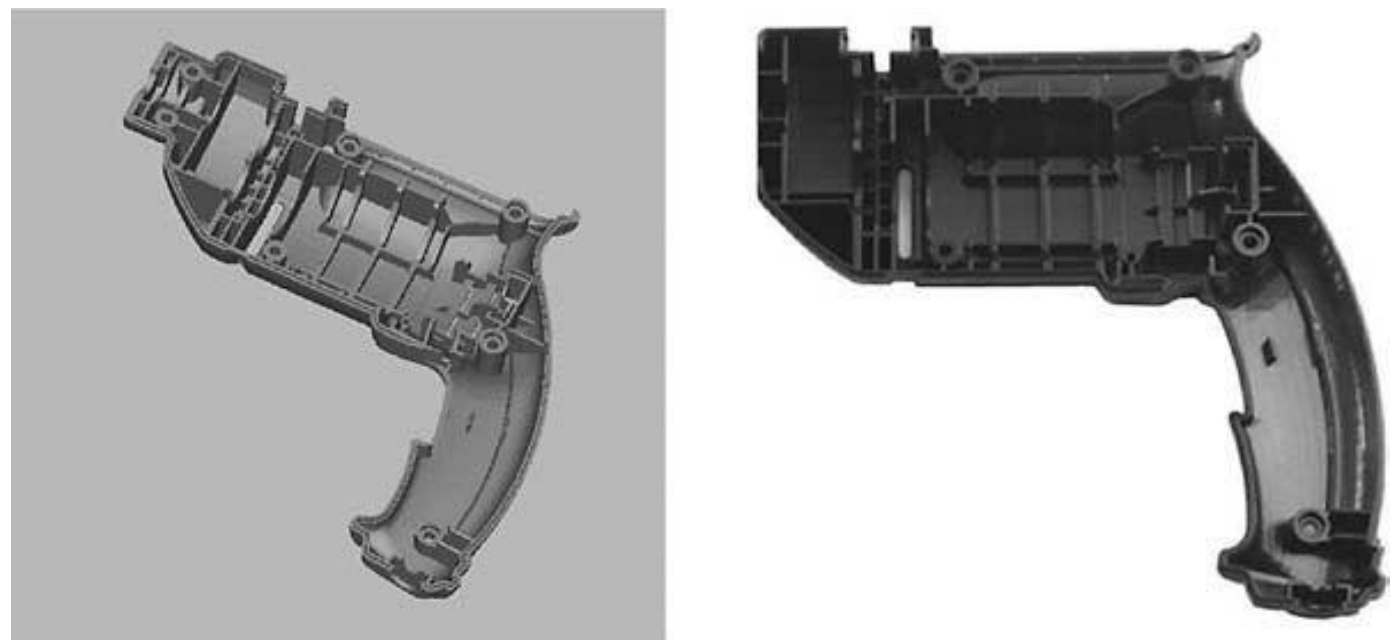

Figura 1 - Modelo virtual (esq.) e protótipo (dir.) de uma carcaça de furadeira.

Fonte: (LIOU, 2008, p. 254)

Segundo a Wohlers Associates Inc., a aplicação mais comum ainda se encontra na produção de modelos funcionais, protótipos de componentes e algumas aplicações estéticas, no entanto mercado para a indústria de manufatura aditiva tem se mostrado muito promissor e cresce substancialmente a cada ano, saindo em $2010 \mathrm{com}$ um crescimento de $24,1 \%$ e um montante de US\$1,325 bilhões para $29,4 \%$ e US\$ 1,714 bilhões em 2011, (WOHLERS, 2012).

Hoje podemos observar um grande número de variações nos processos, bem como nos materiais disponíveis, todos com cada vez maior precisão, velocidade e maior número de materiais possíveis de serem empregados. E muito desse desenvolvimento surge em função de novas demandas, principalmente relacionadas à qualidade das peças, tanto em termos de resolução da superfície, quanto na uniformidade da estrutura e sua resistência (VOLPATO, 2007, p. 12). 
A utilização da impressão 3D que causará maior mudança nas estruturas produtivas convencionais é aquela com a finalidade da fabricação direta de produtos para o mercado, modalidade que já pode ser observada em alguns segmentos específicos em negócios que já funcionam baseados na tecnologia, porém, mesmo com todo avanço tecnológico percebido nos últimos anos, algumas questões ainda dificultam sua aplicação em vários segmentos específicos, especialmente aqueles que tentam utilizá-la para a fabricação direta de produtos para o mercado, pois as impressoras ainda são lentas e o custo das matérias-primas ainda muito elevado se comparados aos métodos convencionais de produção e os materiais utilizados nestes (HOPKINSON e DIKENS, 2001, p. 200).

\subsection{Materiais e tecnologias de impressão 3D}

Segundo Wohlers (2012, p. 4), a norma ASTM aprovou os termos para uma definição dos processos de fabricação por adição de material (AM):

- Extrusão de material - processo de fabricação aditiva no qual o material é seletivamente depositado através da extrusão por um bico ou orifício, geralmente o material utilizado neste processo é algum tipo de termoplástico;

- Jato de material - processo de fabricação aditiva no qual gotículas do material construtivo são seletivamente depositadas e curadas com uma luz ultravioleta, neste caso o material é uma resina líquida;

- Jato colante - processo de fabricação aditiva no qual um agente líquido colante é seletivamente depositado para juntar materiais em pó, podendo-se utilizar diversos tipos de pó bem como também existem variações na resina aglutinante;

- Laminação em folhas - processo de fabricação aditiva no qual folhas de um material são coladas para formar um objeto, como no caso anterior, este processo cria um material compósito, formado pela lâmina do material construtivo mais a cola;

- Polimerização em tanque - processo de fabricação aditiva no qual um polímero líquido em um recipiente é seletivamente curado por uma luz fotopolimerizadora, para tanto se utiliza uma resina líquida fotocurável;

- Fusão em cama de pó - processo de fabricação aditiva no qual uma energia térmica funde seletivamente regiões de uma cama de material em pó, podendo-se também utilizar diferentes tipos de pó, como por exemplo, de polímeros, metais, minerais, dentre outros;

- Deposição por energia dirigida - processo de fabricação aditiva no qual uma energia térmica focada é utilizada para fundir materiais pelo derretimento conforme o material em pó vai sendo depositado, aqui também existem muitos tipos diferentes de pó.

Cada um dos termos definidos para classificação das tecnologias citadas determinam apenas os princípios básicos dos processos utilizados pelas impressoras, para cada processo citado, existem inúmeras variações, delineando um universo muito mais amplo do que esta listagem.

Como no caso dos processos, também existe uma grande variedade de materiais para cada tipo de processo, e constantemente aparecem novos materiais, bem como novas aplicações. Apesar desses vários tipos de materiais, podemos agrupá-los conforme alguns critérios, porém o que vem sendo convencionado pela norma é o 
agrupamento da matéria-prima segundo o seu estado, podendo ser baseados em líquidos, sólidos e pós (WOHLERS, 2012, p. 4).

Os materiais sólidos são mais utilizados em forma de filamentos, muito aplicados nos processos de extrusão, que são atualmente os mais populares, e em forma de lâminas, para processos baseados em soldagem recorte de lâminas na formação das camadas. Já os líquidos geralmente são resinas fotossensíveis à base epóxi, vinílica ou acrílica, curadas por um laser ou uma luz ultravioleta, que são mais comumente usados na estereolitografia e na jato de tinta. Já nos baseados em pó temos uma série de materiais disponíveis, os mais comuns são os polímeros, resinas e até metais. 0 desenvolvimento de novos materiais para impressão 3D vem aumentando drasticamente, impulsionado pela popularização e disseminação da tecnologia nos últimos tempos, podemos esperar a cada dia novos tipos de materiais para mais aplicações.

\section{ESTUDO DE CASO: IMPRESSÃO 3D NA JOALHERIA EM BELO HORIZONTE}

A fabricação de joias convencional possui algumas etapas do seu processo que o torna característico para o segmento, basicamente após o projeto da joia é feita uma peça modelo, a partir dela é feito um molde em silicone para que sua geometria seja reproduzida em cera na quantidade da série a ser produzida, estas peças em cera são revestidas de gesso para então receber a fundição do metal que derrete a cera dentro do gesso, preenchendo toda a cavidade e formando assim a peça final. Este processo é denominado fundição com cera perdida, o mais utilizado pelas fabricantes do segmento.
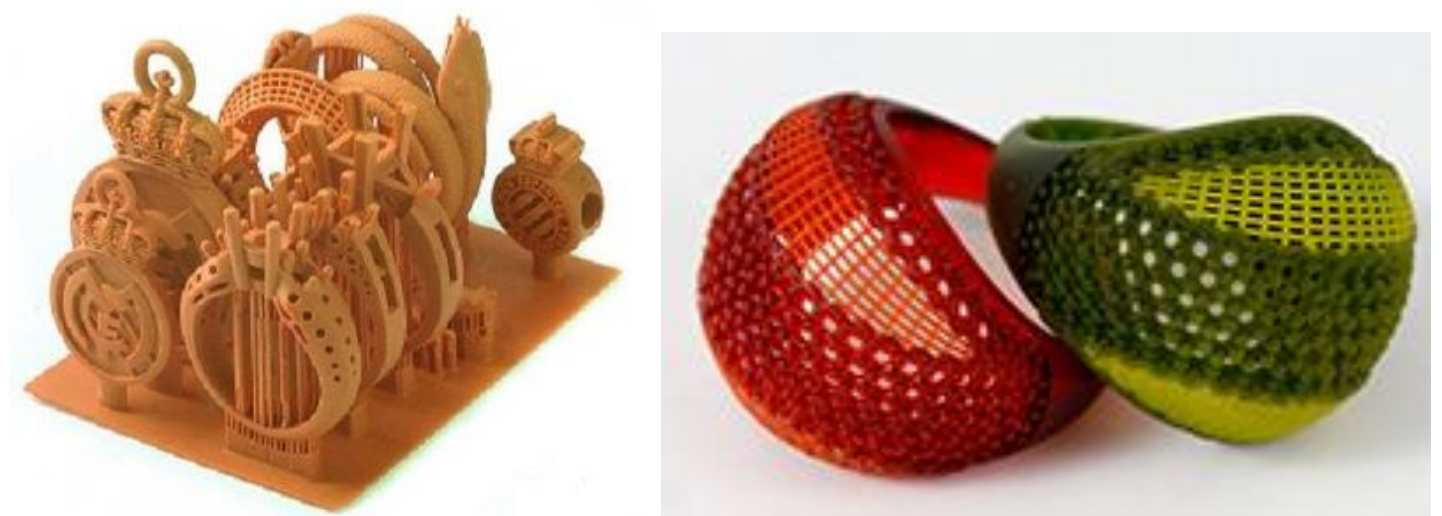

Figura 2 - Protótipos de joias variadas fabricados em impressora 3D e Protótipos de anéis fabricados em impressora 3D respectivamente.

Fonte: (SCULPTEC, 2013) e (VORLONTEC, 2013).

A impressão 3D na joalheria, como em outras aplicações, começou sendo empregada como ferramenta de construção de modelos para as fases mais próximas ao desenvolvimento de produto. Na joalheria, devido a algumas características específicas como valor do produto, complexidade da geometria, pequenas séries de produção, e por boa parte do trabalho ser manual, sua aplicação foi facilitada, se tornando importante ferramenta para a preparação das peças para a fundição. Atualmente esta utilização já realidade, as empresas fabricantes já incorporaram a técnica como parte do processo produtivo, particularmente aplicada na fabricação da peça modelo, evitando assim o trabalho do modelador e conseguindo ganho na qualidade, tempo e complexidade formal. 
Uma extensão da aplicação já pode ser observada em alguns casos específicos, onde se imprime não a peça modelo, mas as peças diretamente em cera para serem utilizadas diretamente na fundição da peça final, descartando assim a etapa de fabricação do molde em silicone. Um próximo passo na ampliação da utilização da tecnologia na joalheria seria a impressão direta da peça final, em metal, porém sua viabilidade ainda depende de melhorias nos processos e nos materiais empregados, fora questões mercadológicas, como escassez de fornecedores, que ainda são empecilhos para a ampliação da aplicação da tecnologia.

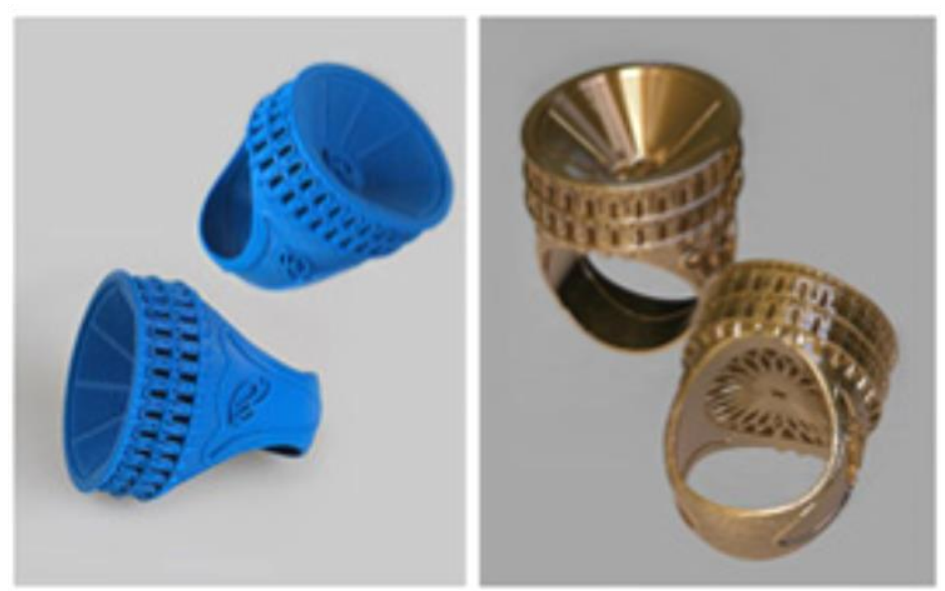

Figura 3 - Anel em duas fases de fabricação distintas, peça impressa em cera e peça fundida, respectivamente.

Fonte: (SOLIDSCAPE, 2013)

As empresas prestadoras de serviço ainda enfrentam muitos problemas, o mercado de fornecimento de maquinário e insumos é muito precário e ainda não está bem desenvolvido, são poucas as empresas atuantes no setor. $O$ fornecimento de material para impressão é feito exclusivamente pelas empresas fabricantes do maquinário, e eles são desenvolvidos com base em uma política protecionista, ou seja, as impressoras contêm mecanismos para travar a utilização de insumos de outros fornecedores, permitindo apenas aqueles produzidos pela fabricante da máquina.

Desta forma estas empresas fornecedoras garantem uma demanda futura de venda de insumos para cada impressora colocada no mercado, o cliente fica obrigado a comprar material exclusivamente da fabricante, pagando preços abusivos bem como fazer manutenções arbitrárias também a custos muito altos e, como eles não têm outra opção. O fornecedor fica protegido e não oferece nenhuma garantia de qualidade do produto ou regularidade do fornecimento, o que os obriga a trabalhar com altos níveis de estoque, deixando o prestador de serviços dependente do fornecedor.

A aplicação da impressão 3D nos processos de fabricação em joalheria é muito exigente tecnicamente em função da característica do produto, as peças são muito pequenas e com espessuras muito finas, que exigem alta precisão e excelente acabamento superficial, necessitando então alta qualidade na impressão, ou seja, alta 
precisão e maior resolução ${ }^{2}$ possível, questão crucial que ainda exige melhorias nas técnicas de impressão.

A velocidade, precisão e resolução das impressoras ainda são um ponto crítico para a ampliação da utilização da impressão 3D, principalmente para fabricação direta das peças, pois ainda não se consegue uma boa qualidade de acabamento, especialmente entre as camadas construtivas, comprometendo a uniformidade da superfície e deixando um leve "serrilhado" na peça, bem como o processo de fabricação ainda é bastante lento e um incremento na velocidade potencializaria a capacidade produtiva das impressoras, tornando-as mais competitivas se comparada a outros métodos tradicionais de produção.

Essa situação confortável para os fornecedores, a falta de concorrentes para o fornecimento de maquinário e de insumos, acaba inibindo o desenvolvimento de melhorias e novas tecnologias.

No Brasil existem muito poucas iniciativas para o desenvolvimento de máquinas de impressão 3D nem tampouco pesquisas e investimentos voltados para o desenvolvimento de novas matérias primas para servir como alternativa àquelas já disponíveis no mercado.

O que se observa são apenas algumas iniciativas pontuais, partindo de entusiastas, tentativas de desenvolvimento de impressoras 3D mais "abertas" com peças de reposição e sem travas para blindar o mercado de suprimentos, porém estas são iniciativas amadoras, não possuem uma empresa que dê garantias futuras como, por exemplo, de fornecimento de peças de reposição, componentes, insumos, entre outros.

Também não se observam pesquisas para o desenvolvimento de matérias primas, quando estas ocorrem, são pesquisas feitas em universidades onde os resultados ficam restritos à academia, sem nenhum tipo de foco mercadológico, não se faz uma ponte com o mercado ou a iniciativa privada para que o produto seja disponibilizado e se torne uma opção de mercado.

O alto custo das matérias primas é o principal dificultador para as empresas de prestação de serviço para o segmento joalheiro, e também para a popularização da utilização da impressão tridimensional em geral. O impacto do alto custo dos materiais ainda é determinante na composição de custo das peças produzidas, o que deixa o mercado bastante restrito.

$\mathrm{Na}$ impressão para joalheria, as mesmas características que tanto exigem tecnicamente das impressoras, também são as que tornam viável sua utilização neste momento. As peças são geralmente muito pequenas e com espessuras muito finas, 0 que implica em baixo consumo de material na confecção da peça modelo, algumas vezes até da série em cera, fazendo com que a peça fique a um custo viável.

Como o material é o mais impactante no custo da peça, as empresas procuram aperfeiçoar ao máximo sua utilização, e algumas desenvolveram pequenas técnicas específicas para o segmento, que auxiliam na redução da utilização do material e a qualidade de acabamento da peça, principalmente no que se refere ao planejamento

\footnotetext{
2 Resolução da impressora é a quantidade de pontos de material depositados em um determinado volume, quanto maior a resolução, mais pontos por unidade de volume e maior a precisão, fidelidade e acabamento superficial da peça.
} 
dos suportes ${ }^{3}$. E como não se tem formas de se desviar do alto custo dos materiais, as empresas procuram trabalhar outros pontos como a redução na mão de obra, a fim de conseguir uma redução no seu custo operacional.

\section{ANÁLISE}

A aplicação da impressão tridimensional nos processos de produção de joias já é viável e se encontra sedimentado na cidade de Belo Horizonte, podemos observar que as empresas prestadoras de serviço de impressão, têm claramente um foco neste segmento e se especializaram para atendê-lo mais adequadamente, tanto com maquinário específico, quanto com a adaptação de alguns procedimentos de impressão com o objetivo de melhorar a qualidade para a fabricação de joias.

A impressão encontrou seu espaço sendo empregada em uma etapa chave da joalheria, a modelagem da peça a ser produzida, uma utilização ainda muito pontual e que tem espaço para ser ampliada, como por exemplo, na confecção de toda a série de fabricação já em cera para posteriormente serem feitos os moldes e fundidas as peças.

Ainda existem muitas restrições na utilização da tecnologia, a maioria delas relacionadas ao custo de fabricação, como o preço de algumas matérias-primas, custo do maquinário, velocidade e qualidade superficial (resolução) de vários equipamentos. A principal delas, ainda é o alto preço das matérias primas utilizadas, pois é a parte mais impactante na composição do custo e o maior responsável pela elevação no preço das peças, o que inviabiliza a utilização da tecnologia para muitas aplicações.

Este alto custo da matéria prima se deve basicamente às travas que as impressoras possuem para impedir que o fabricante possa utilizar material de outros fornecedores, ou seja, as fabricantes do maquinário desenvolvem sistemas de bloqueio, muitos deles abusivos, para que os usuários sejam obrigados a comprar insumos exclusivamente deles, garantindo assim uma cota sobre o fornecimento desses materiais.

Este fator é um dos principais responsáveis pela lentidão na ampliação da utilização das impressoras no segmento joalheiro, com custos mais baixos, a participação da impressão poderia ser muito maior, expandindo sua utilização em outras etapas do processo produtivo, portanto, é fundamental que o mercado de suprimentos para a impressão 3D seja desenvolvido, particularmente com o surgimento de novos fornecedores e novos materiais.

Assim, o desenvolvimento de pesquisas com este objetivo é de fundamental importância para que a tecnologia se torne mais abrangente, chegando a segmentos ainda não contemplados pelos seus benefícios e novas oportunidades que a impressão tridimensional pode proporcionar.

\footnotetext{
${ }^{3}$ Suportes são depósitos adicionais de material que depois da impressão são removidos, são utilizados para tornar possível a impressão de partes da peça que ficariam sem apoio durante o processo de fabricação por camadas.
} 
Tabela 1 - Tabela Pontos críticos x Oportunidades

\begin{tabular}{|l|l|}
\hline Pontos Críticos & Oportunidades \\
\hline Baixa competitividade no setor. & Entrada de novos Players. \\
\hline$>$ Travas nos equipamentos. & $\begin{array}{l}\text { > Mudança da política de "fidelização" } \\
\text { dos clientes. }\end{array}$ \\
\hline$>$ Custo dos insumos. & > Entrada de novos fornecedores no setor. \\
\hline $\begin{array}{l}\text { > Maquinário pouco especializado, } \\
\text { resolução x velocidade de impressão. }\end{array}$ & $\begin{array}{l}\text { > Desenvolvimento de impressoras mais } \\
\text { especializadas para a produção de joias. }\end{array}$ \\
\hline
\end{tabular}

Fonte: Elaborada pelo autor, com base na pesquisa realizada.

\section{CONSIDERAÇÕES FINAIS}

A impressão 3D vem sendo aplicada em vários segmentos e promovendo diversas mudanças nos seus processos, ela teve sua aplicabilidade viabilizada inicialmente no desenvolvimento de novos produtos, porém vem gradualmente ocupando espaço e tomando cada vez mais etapas dos processos produtivos.

Apesar de ter sua utilização ainda restrita a alguns segmentos em função da baixa competitividade, principalmente no que tange os custos em relação aos métodos de fabricação tradicionais, ela está em constante crescimento.

Atualmente podemos ver aplicações onde ela permite uma fabricação digital direta, ou seja, fabricar diretamente a peça projetada sem que sejam necessárias etapas intermediárias do processo produtivo, partindo-se do projeto diretamente para a peça final destinada para o consumo e não mais apenas para a confeç̧ão de protótipos como no início de sua utilização.

Essa expansão da utilização da impressão 3D também pode ser forte aliada nas questões relativas à sustentabilidade, vez que com a exclusão de etapas produtivas, também se diminuem os gastos com insumos nestas etapas, como por exemplo, a confecção de moldes para a fundição no caso da joalheria.

A acessibilidade das impressoras está levando a um aumento do acesso à tecnologia, possibilitando que mais pessoas possam produzir peças para utilizá-las na solução de problemas diários ou mesmo para viabilizar suas ideias e comercializá-las, democratizando setores de atividades até então dominados exclusivamente por empresas, governos ou outras instituições, o que pode gerar mudanças revolucionárias quando disponibilizadas para pessoas comuns.

A popularização da capacidade produtiva facilita a produção dos artefatos, o que contribui para uma relativa diminuição a importância do produto, da coisa, do material, ao mesmo tempo em que tende a aumentar a importância e o valor do imaterial, da ideia, do conceito. Podemos entender essa imaterialidade, tão mencionada no contexto da sustentabilidade, agora também presente no próprio design, que a cada dia é entendido mais como processo e menos como resultado, seja ele material ou não.

Nesse sentido, o design entra em um momento de rever suas fronteiras, delinear seus espaços, descentralizando sua ação do produto e concentrando-a na solução, ampliando sua abrangência no sentido da solução integradora gerada a partir do seu posicionamento como um processo para promover a melhoria do bem estar humano. 


\section{REFERÊNCIAS}

ANDERSON, C. Makers: A nova revolução industrial. Rio de janeiro: Elsevier, 2012.

BOURELL, D. L. et al. A Brief History of Additive Manufacturing and the 2009 Roadmap for Additive Manufacturing: Looking Back and Looking Ahead. RapidTech 2009: USTURKEY Workshop on Rapid Technologies, Istanbul, 24 setembro 2009. 7.

BQZ. BQZ Comercial.htm. BQZ Comercial, 2013. Disponivel em: <http://www.bqz.com.br>. Acesso em: 02 outubro 2013.

DAY, P. Will 3D printing revolutionise manufacturing? BBC News, 2011. Disponivel em: <http://www.bbc.co.uk/news/business-14282091>. Acesso em: 27 abril 2013.

DIMITROV, D.; SCHREVE, K.; DE BEER, N. Advances in three dimensional printing - state of the art and future perspectives. Rapid Prototyping Journal, Stellenbosch, v. 12, n. 3, p. 12, 2006. ISSN 1355-2546.

DRIZO, A.; PEGNA, J. Environmental impacts of rapid prototyping: an overview of research to date. Rapid Prototyping Journal, Canada, 2006. 64-71.

GERSHENFELD, N. How to Make Almost Anything: The Digital Fabrication Revolution. Foreign Affairs, v. 91, n. 6, p. 60-75, Novembro 2012.

HOPKINSON, N.; DIKENS, P. Rapid prototyping for direct manufacture. Rapid Prototyping Journal, v. 7, n. 4, p. 197-202, 2001. ISSN 1355-2546.

LIOU, F. W. Rapid prototyping and engineering applications: a toolbox for prototype development. Londres: CRC Press, 2008.

MANZINI, E. Metaprojeto hoje: guia para uma fase de transição. In: DE MORAES, D. Metaprojeto: o design do design. São Paulo: Blücher, 2010. p. 215.

MANZINI, E.; VEZZOLI, C. O desenvolvimento de produtos sustentáveis. São Paulo: Edusp, 2002.

SCULPTEC. Sculptec -.htm. Sculptec, 2013. Disponivel em: <http://sculptec.com.br>. Acesso em: 02 outubro 2013.

SOLIDSCAPE. Rapid Prototyping 3D Prototyping Wax Casting Stereolithography.htm. Solidscape, 2013. Disponivel em: <http://www.solid-scape.com/>. Acesso em: 20 novembro 2013.

TAKAGAKI, L. K. CAPÍTULO 3. Tecnologia de Impressão 3D. Revista Inovação Tecnológica, São Paulo, v. 2, n. 2, p. 28 - 40, dez 2012. ISSN 21792895.

VOLPATO, N. Prototipagem Rápida: Tecnologias e Aplicações. São Paulo: Edgard Blücher, 2007.

VORLONTEC. Vorlontec.htm. Vorlontec, 2013. Disponivel em: <http://www.vorlontec.com.br>. Acesso em: 02 outubro 2013.

WOHLERS, T. Recent trends in additive manufacturing. 17th European Forum on Rapid Prototyping and Manufacturing, Paris, 12-14 junho 2012. 6. 